\title{
Analysis of the site for second-strand initiation during replication of the Streptomyces plasmid pIJ101
}

\author{
SARA ZAMAN, ${ }^{1} \dagger$ LyNDSAY RADNEDGE, ${ }^{2} \ddagger$ HILARY RICHARDS ${ }^{1}$ and John M. WARD ${ }^{2 *}$ \\ ${ }^{1}$ Department of Biology, and ${ }^{2}$ Department of Biochemistry and Molecular Biology, University College, Gower Street, \\ London WCIE 6BT, UK
}

(Received 13 August 1992; revised 1 December 1992; accepted 17 December 1992)

\begin{abstract}
The indigenous plasmid plJ101 is the parent of many cloning vectors used in Streptomyces. One early pIJ101 derivative, pIJ702, has been particularly widely used. pIJ702 lacks sti:cop/korB and accumulates single-stranded DNA (ssDNA). The $1.2 \mathrm{~kb} B c l I-B c l I$ sti: $\operatorname{cop} / k o r B$ and $0.7 \mathrm{~kb}$ SpeI-BclI sti regions were isolated from pIJ101 and cloned into pIJ702 at the PstI site in both orientations. No ssDNA was detected in constructs containing sti present in its correct orientation with respect to the basic replicon, with or without $\operatorname{cop} / k o r B$. Constructs which contained $s t i$ in the reverse orientation did accumulate ssDNA. Thus, $s t i$ is only active as the site for second-strand synthesis in its natural orientation. Furthermore, sti inserted in either orientation into the structurally unstable pIJ702-pUC8 shuttle vectors prevented them from rearranging in S. lividans. The sti function was defined to a $0.53 \mathrm{~kb}$ SpeI-SacII fragment and the probable site for second-strand initiation (ssi) was identified.
\end{abstract}

\section{Introduction}

The Streptomyces plasmid pIJ101 $(8.9 \mathrm{~kb})$ is a high-copynumber (40-300 copies per chromosome), broad-hostrange plasmid (Kieser et al., 1982). Kendall \& Cohen (1988) have determined the complete nucleotide sequence of pIJ101 and have analysed it for open reading frames (ORFs) with respect to the available information about the genetic properties of the plasmid. Currently, more is known about the biology of pIJ101 than any other Streptomyces plasmid.

pIJ101 probably replicates using a rolling-circle mechanism via a single-stranded DNA (ssDNA) intermediate (Pigac et al., 1988; Gruss \& Ehrlich, 1989). ssDNA intermediates corresponding to one strand of a plasmid monomer have also been discovered in plasmids isolated from Bacillus subtilis (te Riele et al., 1986a, $b$; Devine et al., 1989), Staphylococcus aureus (te Riele et al., 1986a, b; Gros et al., 1987; Gruss et al., 1987; Boe et al., 1989; Novick, 1989) and Streptococcus pneumoniae (del Solar et al., 1987). Such plasmids which replicate using a

\footnotetext{
*Author for correspondence. Tel. 0713877050 (ext. 2242); fax 071 3807193.

$\dagger$ Present address: Institute of Molecular and Cell Biology, National University of Singapore, Kent Ridge Crescent, Singapore 0510.

$\ddagger$ Present address: Laboratory of Chromosome Biology, NCI Frederick Cancer Research Center, Frederick, MD 21701, USA.

Abbreviation: ssDNA, single-stranded DNA.
}

rolling-circle mechanism can be classified according to the homologies of their replication (Rep) proteins and the position of the plus origin with respect to the replication (rep) gene (Gruss \& Ehrlich, 1989). Gruss \& Ehrlich (1989) found that the predicted amino acid sequence of the pIJ101 Rep protein active site is similar to those found in several other plasmid-encoded Rep proteins which bind to $\mathrm{pC} 194-$ like plus origins. They also suggested that the pIJ101 plus origin lies upstream of the rep ORF where there is structural similarity to the Staph. aureus $\mathrm{pC} 194$ plus origin, although it is now known that the pIJ101 plus origin is not located here (Zaman et al., 1993).

Derivatives of pIJ101 have been constructed for cloning purposes and one, pIJ702 (Katz et al., 1983), has been used extensively as a cloning vector in Streptomyces (for reviews see Tomich, 1988; Chater, 1990). pIJ702 contains the $2.0 \mathrm{~kb}$ BalI-SacII region of pIJ101 found to be essential for maintenance and replication in S. lividans (Zaman et al., 1993). pIJ702 is known to accumulate ssDNA molecules (Deng et al., 1988; Pigac et al., 1988), which are the presumed intermediates in plasmid replication (Pigac et al., 1988; Gruss \& Ehrlich, 1989). Thus, pIJ702 probably lacks the primary site for secondstrand initiation (ssi) but contains one or more sequences which can act as weak or inefficient sites for secondstrand synthesis, thereby allowing double-stranded pIJ702 to form but also keeping a pool of ssDNA present in the cell. Such ssDNAs are likely to be highly 
Table 1. Bacterial strains and plasmids

\begin{tabular}{|c|c|c|}
\hline Strain or plasmid & Description* & Reference \\
\hline Escherichia coli JM107 & $\begin{array}{l}\Delta(\text { lac-proAB }) \text { endAl gyrA96 thi hsdR17 supE44 relA1 } \\
\lambda^{-}\left[F^{\prime} \text { traD36 proAB } B^{+} \text {lac } \mathrm{I}^{\mathrm{q}} \mathrm{Z} \Delta \mathrm{M} 15\right]\end{array}$ & Yanisch-Perron et al. (1985) \\
\hline Streptomyces lividans TK24 & str-6 SLP2- SLP3- & Hopwood et al. (1983) \\
\hline pUC8 $(2 \cdot 7 \mathrm{~kb})$ & $\mathrm{Ap}^{\mathrm{r}} \mathrm{LacZ}^{\prime}$ & Vieira \& Messing (1982) \\
\hline pUC19 $(2 \cdot 7 \mathrm{~kb})$ & $\mathrm{Ap}^{\mathrm{r}} \mathrm{LacZ}^{\prime}$ & Yanisch-Perron et al. (1985) \\
\hline pBluescript II $(3.0 \mathrm{~kb})$ & Ap LacZ $^{\prime}$ & Stratagene \\
\hline pIJ101 $(8.9 \mathrm{~kb})$ & $s t i^{+} \operatorname{cop} /$ kor B $^{+}$ & Kieser et al. (1982) \\
\hline pIJ303 $(10 \cdot 8 \mathrm{~kb})$ & $\mathrm{Tsr}^{\mathrm{r}} \operatorname{sti}^{+} \operatorname{cop} /$ kor $^{+}$ & Kieser et al. (1982) \\
\hline pIJ702 $(5.8 \mathrm{~kb})$ & $\mathrm{Tsr}^{\mathrm{r}} \mathrm{Mel}^{+}$sti $^{-} \operatorname{cop} /$ kor $B^{-}$ & Katz et al. (1983) \\
\hline pQR200 (3.9 kb) & $\begin{array}{l}1.2 \mathrm{~kb} \mathrm{Bcll-Bcll} \text { sti:cop/korB fragment in pUC8 } \\
\text { BamHI site }\end{array}$ & This work \\
\hline pQR410a $(9 \cdot 7 \mathrm{~kb})$ & pQR200 in pIJ702 PstI site (sti ${ }^{\mathrm{rev}} \operatorname{cop} /$ kor $\left.^{+}\right)$ & This work \\
\hline $\mathrm{pQR} 410 \mathrm{~b}(7 \cdot 0 \mathrm{~kb})$ & $\begin{array}{l}1.2 \mathrm{~kb} B c l \mathrm{I}-B c l \mathrm{I} \text { fragment in pIJ702 PstI site }\left(s t i^{\text {rev }}\right. \\
\left.\text { cop/kor } B^{+}\right)\end{array}$ & This work \\
\hline pQR411a $(9.7 \mathrm{~kb})$ & pQR200 in pIJ702 PstI site $\left(s t i^{+}\right.$cop/kor $\left.B^{+}\right)$ & This work \\
\hline $\mathrm{pQR} 411 \mathrm{~b}(7 \cdot 0 \mathrm{~kb})$ & $\begin{array}{l}1.2 \mathrm{~kb} \mathrm{BclI}-B c I \text { fragment in pIJ } 702 \text { PstI site }\left(s t i^{+}\right. \\
\left.\text {cop } / \text { kor }^{+}\right)\end{array}$ & This work \\
\hline pQR417 (3.4 kb) & $\begin{array}{l}0.7 \mathrm{~kb} \text { Spel-Bcll sti fragment in pUC19 } \mathrm{Xbal} / \mathrm{BamHI} \\
\text { sites }\end{array}$ & This work \\
\hline pQR421a $(9 \cdot 2 \mathrm{~kb})$ & pQR417 in pIJ702 PstI site $\left(s t i^{+}\right.$cop/korB $\left.{ }^{-}\right)$ & This work \\
\hline $\mathrm{pQR} 421 \mathrm{~b}(6.5 \mathrm{~kb})$ & $\begin{array}{l}0.7 \mathrm{~kb} S p e \mathrm{I}-B c l \mathrm{I} \text { fragment in pIJ } 702 \text { PstI site }\left(s_{t i}^{+}\right. \\
\left.\text {cop } / \text { kor }^{-}\right)\end{array}$ & This work \\
\hline pQR422a $(9 \cdot 2 \mathrm{~kb})$ & pQR417 in pIJ702 PstI site (sti ${ }^{\text {rev }}$ cop/korB $\left.{ }^{-}\right)$ & This work \\
\hline $\mathrm{pQR} 422 \mathrm{~b}(6.5 \mathrm{~kb})$ & $\begin{array}{l}0.7 \mathrm{~kb} S p e \mathrm{I}-B c l \mathrm{I} \text { fragment in } \mathrm{pIJ} 702 \text { PstI site }\left(s t i^{r e v}\right. \\
\left.\text { cop } / \text { kor }^{-}\right)\end{array}$ & This work \\
\hline pQR437 (3.3 kb) & $\begin{array}{l}0.6 \mathrm{~kb} \text { SpeI-SacI sti fragment in pUC19 XbaI/SacI } \\
\text { sites }\end{array}$ & This work \\
\hline pQR438 $(3.23 \mathrm{~kb})$ & $0.53 \mathrm{~kb}$ SpeI-SacII sti fragment in pUC19 & This work \\
\hline pQR441a $(9 \cdot 1 \mathrm{~kb})$ & pQR437 in pIJ702 PstI site $\left(s t i^{+}\right.$cop $\left./ k_{\text {kor }}{ }^{-}\right)$ & This work \\
\hline pQR441b $(6.4 \mathrm{~kb})$ & $\begin{array}{l}0.6 \mathrm{~kb} \text { SpeI-SacI fragment in pIJ } 702 \text { PstI site }\left(s t i^{+}\right. \\
\left.\text {cop/kor } B^{-}\right)\end{array}$ & This work \\
\hline pQR442a $(9 \cdot 1 \mathrm{~kb})$ & pQR437 in pIJ702 PstI site (stirev cop/kor $\left.B^{-}\right)$ & This work \\
\hline pQR443a $(9.0 \mathrm{~kb})$ & pQR438 in pIJ702 PstI site $\left(s t l^{+}\right.$cop/korB $\left.{ }^{-}\right)$ & This work \\
\hline pQR443b $(6.33 \mathrm{~kb})$ & $\begin{array}{l}0.53 \mathrm{~kb} \text { SpeI-SacII fragment in pIJ702 PstI site }\left(s t i^{+}\right. \\
\left.\text {cop/kor } B^{-}\right)\end{array}$ & This work \\
\hline pQR444a $(9 \cdot 0 \mathrm{~kb})$ & pQR438 in pIJ702 PstI site (sti $\left.{ }^{r e v} \operatorname{cop} / k o r B^{-}\right)$ & This work \\
\hline
\end{tabular}

${ }^{*} \mathrm{Ap}^{\mathrm{r}}$, ampicillin resistance: $\mathrm{Tsr}^{\mathrm{r}}$, thiostrepton resistance: Mel, tyrosinase determinant; LacZ, $\beta$-galactosidase determinant. sti, strong incompatibility (Deng et al., 1988), shown in this work to contain the site for second-strand initiation $(s s i)$; $s t i^{+}, s t i$ in the correct orientation with respect to the basic replicon; $s t i^{\text {rev }}$, sti in the reverse orientation with respect to the basic replicon; $s t t^{-}$, absence of sti. cop/korB, repressor of kilB (Kendall \& Cohen, 1987; Stein et al., 1989; Stein \& Cohen, 1990; Zaman et al., 1992); cop/kor $B^{+}$, presence of $\operatorname{cop} /$ kor $B$ gene; $\operatorname{cop} / k o r B^{-}$, absence of $\operatorname{cop} / k o r B$ gene.

recombinogenic and it may be this property which leads to the rapid breakdown of some pIJ702-based vectors (Pigac et al., 1988). In support of this hypothesis, Pigac et al. (1988) showed that a shuttle vector consisting of the $S$. lividans plasmid $\mathrm{pIJ} 350$ and the Escherichia coli plasmid pBR322 was structurally unstable and accumulated ssDNA in $S$. lividans. Similarly, Lee et al. (1986) stated that a shuttle vector consisting of pIJ702 and the $E$. coli plasmid pUC12 was structurally unstable and induced deletions in $S$. lividans. Inefficient conversion of ssDNA intermediates has also been reported to underlie plasmid structural instability in other organisms. For example, in Staph. aureus pT181-like plasmids, palA is needed for normal replication and stability since rearrangements affecting palA result in ssDNA accumulation and plasmid structural instability (Gruss et al., 1987; Novick, 1989). Similarly, deletions affecting the ssi region of the streptococcal plasmid pLS1 cause ssDNA accumulation and plasmid structural instability (del Solar et al., 1987).

Deng et al. (1988) identified a non-coding region of pIJ101 DNA, called $s t i$, which causes strong incompatibility when present in its natural orientation with respect to the basic replicon. A pair of plasmids can coexist in the same host if they both possess sti in the correct orientation $\left(\mathrm{Sti}^{+}\right)$, or both possess $s t i$ in the reverse orientation $\left(\mathrm{Sti}^{\text {rev }}\right)$ or both lack $s t i\left(\mathrm{Sti}^{-}\right) . \mathrm{Sti}^{+}$and $\mathrm{Sti}^{-}$plasmids cannot co-exist in the same cell: if they occur together the $\mathrm{Sti}^{+}$plasmid is retained while the $\mathrm{Sti}^{-}$ plasmid is eventually lost. Sti ${ }^{-}$plasmids accumulate more ssDNA than $\mathrm{Sti}^{+}$plasmids, implicating $s t i$ as the site where second-strand synthesis is initiated. Sti therefore contains the minus origin. Deng et al. (1988) suggested that Cop, a protein which is encoded by a gene adjacent 
to $s t i$, is a trans-acting negative regulator which decreases the copy number of $\mathrm{Sti}^{+}$plasmids by inhibiting the initiation of second-strand synthesis at sti. Mapping studies indicate that cop occupies the same site on pIJ101 as another characterized gene called $\operatorname{kor} B$ (Kendall \& Cohen, 1988). KorB repress the transcription of kilB, a gene necessary for normal intra-mycelial plasmid transfer (Kendall \& Cohen, 1987; Stein et al., 1989; Stein \& Cohen, 1990; Zaman et al., 1992). This paper describes the characterization of the primary site for second-strand synthesis of pIJ101 and shows that Cop (KorB) does not regulate the conversion of ssDNA intermediates to the double-stranded plasmid form.

\section{Methods}

Bacterial strains and plasmids. Table 1 contains the description of bacterial strains and plasmids used in this study.

Media and growth conditions. E. coli JM107 was grown on nutrient agar plates or in nutrient broth overnight at $37^{\circ} \mathrm{C}$. These media were supplemented with ampicillin ( $500 \mu \mathrm{g} \mathrm{ml}^{-1}$ in solid media or $50 \mu \mathrm{g} \mathrm{ml}^{-1}$ in liquid media), IPTG $\left(40 \mu \mathrm{g} \mathrm{ml}^{-1}\right)$ and X-Gal $\left(80 \mu \mathrm{g} \mathrm{ml}^{-1}\right)$ when necessary. S. lividans TK24 was grown on R2YE agar (Hopwood et al., $1985)$ or malt extract/yeast extract agar $(2.4 \%, w / v$, Difco malt extract; $0.5 \%, w / v$, Oxoid yeast extract; $2 \%, w / v$, Bactoagar) at $30^{\circ} \mathrm{C}$ until sporulation (typically one week). For liquid cultivation, $S$. lividans TK24 was grown in YEME (Hopwood et al., 1985) for 2-3 d or in malt extract/peptone medium $(2 \%, w / v$, glycerol; $1 \%, w / v$, Oxoid malt extract; $1 \%$, w/v, Difco Bacto-peptone; $0.714 \%$, w/v, $\mathrm{K}_{2} \mathrm{HPO}_{4}$ ) overnight at $30^{\circ} \mathrm{C}$ with good aeration. These media were supplemented with thiostrepton $\left(50 \mu \mathrm{g} \mathrm{ml}^{-1}\right.$ in solid media and $5 \mu \mathrm{g} \mathrm{ml}^{-1}$ in liquid media) when required. Thiostrepton was a kind gift from $S$. J. Lucania (E. R. Squibb \& Sons Inc., NJ, USA).

DNA manipulations. E. coli plasmid DNA was isolated by alkaline lysis (Birnboim \& Doly, 1979). Streptomyces plasmid DNA isolation was based on the alkaline lysis method developed by Kieser (1984). Restriction enzymes and T4 ligase were either made by Dr L. Wallace (University College London) or purchased from Anglian Biotechnology. All restriction digestions and ligations were performed as described by Maniatis et al. (1982). E. coli plasmid transformation was done as described by Morrison (1979), with the cells grown in nutrient broth supplemented with $20 \mathrm{~mm}-\mathrm{MgCl}_{2}$ as described by Hanahan (1983). Preparation and transformation of $S$. lividans TK24 protoplasts were done as described by Bibb et al. (1978) and Thompson et al. (1982).

ssDNA detection. Total DNA was isolated from Streptomyces as described in Hopwood et al. (1985). Agarose gels $(0 \cdot 7 \%$, w/v) were blotted directly onto Bio-Rad Zeta-probe nylon membranes as described by Southern (1975), without prior denaturation of the gel. The Amersham nick-translation kit was used to obtain $\left[\alpha-{ }_{-3}^{32}\right.$ P $] \mathrm{dCTP}$ labelled DNA probes with a specific activity of $>1 \times 10^{8}$ c.p.m. $(\mu \mathrm{g}$ DNA $)^{-1}$. Labelled probe was boiled for $5 \mathrm{~min}$ and placed in a heatsealable plastic bag containing the baked nylon membrane and prehybridization solution $(50 \%, v / v$, formamide; $4 \times \mathrm{SSC} ; 1 \%$, w/v, SDS, $5 \times$ Denhardt's solution, $500 \mu \mathrm{g}$ denatured salmon sperm DNA $\mathrm{ml}^{-1}$ ) to a volume of $150 \mu \mathrm{l}$ per cm of filter [ $1 \times \mathrm{SSC}$ is $0.15 \mathrm{M}-\mathrm{NaCl}$, 0.015 M-trisodium citrate, pH 7.0; $1 \times$ Denhardt's solution is $0.02 \%$ bovine serum albumin, $0.02 \%$ Ficoll, $0.02 \%$ polyvinylpyrrolidone]. The bag was then placed in a $55^{\circ} \mathrm{C}$ oven overnight with shaking. The membrane was removed from the bag, rinsed briefly with $2 \times$ SSC, and then washed successively in each of the following solutions, for $15 \mathrm{~min}$ at room temperature: $2 \times \mathrm{SSC}, 0.1 \%(\mathrm{w} / \mathrm{v}) \mathrm{SDS} ; 0.5 \times \mathrm{SSC}, 0.1 \%$ SDS; and finally $0.1 \times \mathrm{SSC}, 0.1 \%$ SDS. The membrane was then wrapped in Saran wrap and exposed to Fuji RX X-ray film.

\section{Results and Discussion}

\section{Cloning of cop/korB and sti into pIJ702}

The cop/korB: sti region was isolated from pIJ101 on a $1.2 \mathrm{~kb} \mathrm{Bcll}$ fragment and cloned into pUC8 cut with BamHI, producing pQR200. In order to insert both the $c o p / k o r B$ and $s t i$ determinants into $\mathrm{pIJ} 702$, pQR200 was cut with PstI and ligated to pIJ702 also cut with PstI. Recombinant plasmids containing pIJ702 in both orientations were selected in $E$. coli and named pQR410a and pQR411a respectively (Fig. 1). We have previously found that pIJ702-pUC8 shuttle vectors constructed in our laboratory were structurally unstable (R. Barallon, personal communication). The $2.7 \mathrm{~kb}$ pUC8 sequence was therefore excised from $\mathrm{pQR} 410 \mathrm{a}$ and $\mathrm{pQR} 411 \mathrm{a}$ by an EcoRI-HindIII digestion. The remainder of the plasmid was religated using a 58 bp EcoRI-HindIII polylinker isolated from pUC19, producing $\mathrm{pQR} 410 \mathrm{~b}$ and pQR411b (Fig. 1). pQR410a, pQR411a, pQR410b and $\mathrm{pQR} 411 \mathrm{~b}$ all successfully transformed $S$. lividans to thiostrepton resistance and were structurally stable from restriction map analysis.

In order to subclone only the sti determinant, pQR200 was cut with EcoRI and SpeI and the $0.7 \mathrm{~kb}$ fragment containing sti was cloned into pUC19 cut with EcoRI and $X b a \mathrm{I}$, producing $\mathrm{pQR} 417$. To reinsert the sti region into pIJ702, pQR417 was ligated to pIJ702 via the PstI site. Again, constructs in both orientations were found in E. coli, producing $\mathrm{pQR} 421 \mathrm{a}$ and $\mathrm{pQR} 422 \mathrm{a}$ respectively (Fig. 1). To remove the pUC19 component, pQR421a and pQR422a were digested with EcoRI and HindIII, and religated to the EcoRI-HindIII pUC19 polylinker, producing $\mathrm{pQR} 421 \mathrm{~b}$ and $\mathrm{pQR} 422 \mathrm{~b}$ respectively (Fig. 1). $\mathrm{pQR} 421 \mathrm{a}, \mathrm{pQR} 422 \mathrm{a}, \mathrm{pQR} 421 \mathrm{~b}$ and $\mathrm{pQR} 422 \mathrm{~b}$ all successfully transformed $S$. lividans to thiostrepton resistance and were structurally stable from restriction map analysis.

\section{Analysis of ssDNA from plasmids containing sti and cop/korB}

Total DNA was prepared from all eight constructs described above (that is, pQR410a, pQR410b, pQR411a, pQR411b, pQR421a, pQR421b, pQR422a and pQR422b), electrophoresed on an agarose gel (together with lysates containing pIJ702 and pIJ303 as positive and negative controls respectively), and blotted directly onto a nylon membrane without a prior denaturation step. The membrane was then probed with $\left[\alpha_{-}{ }^{32} \mathrm{P}\right] \mathrm{dCTP}$ labelled pIJ702 (Fig. 2). ssDNA was detected in lysates containing $p Q R 410 a / b$ and $p Q R 422 a / b$ but not in 

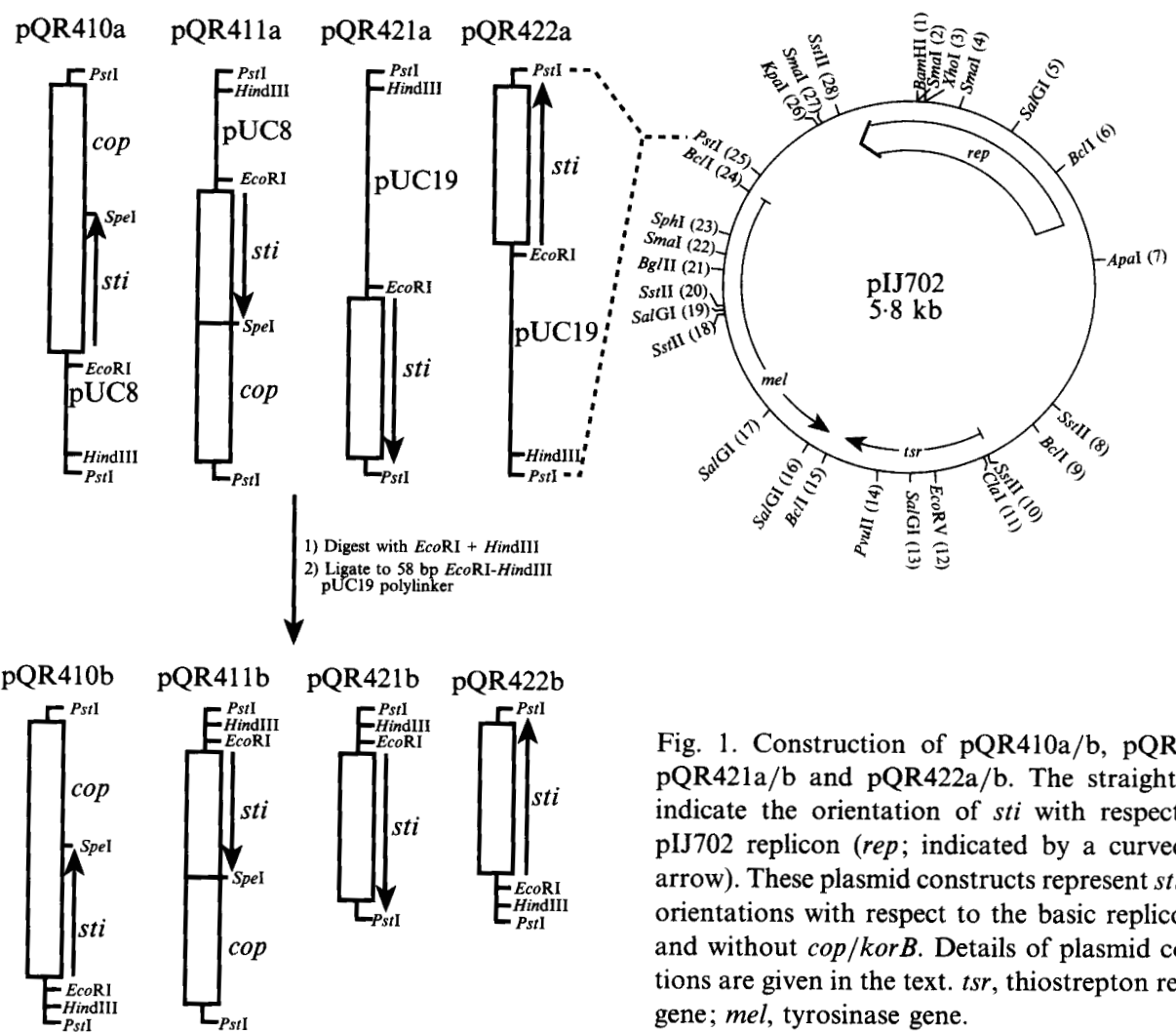

(a)

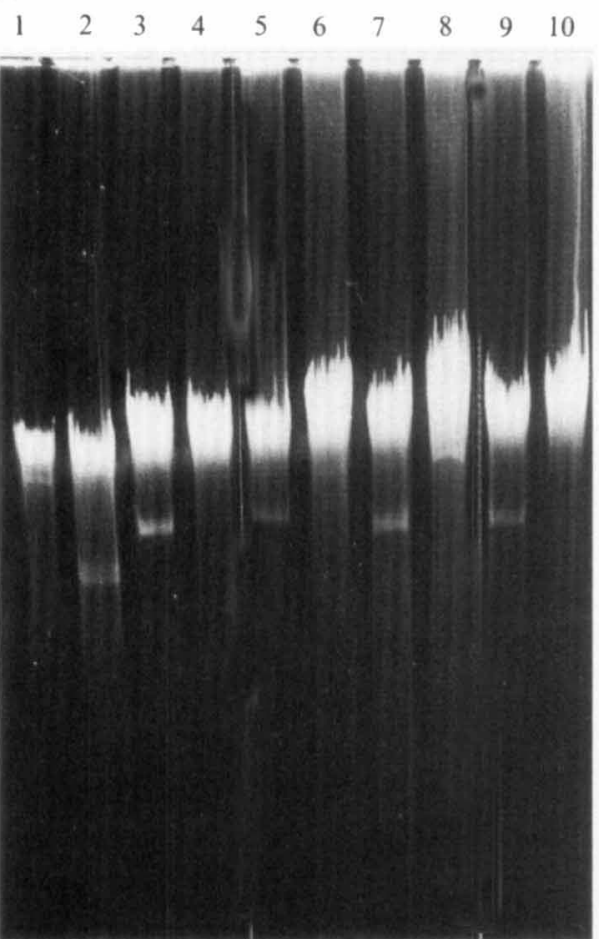

Fig. 1. Construction of $p Q R 410 a / b, p Q R 411 a / b$, $p Q R 421 a / b$ and $p Q R 422 a / b$. The straight arrows indicate the orientation of $s t i$ with respect to the pIJ702 replicon (rep; indicated by a curved broad arrow). These plasmid constructs represent st $i$ in both orientations with respect to the basic replicon, with and without $\operatorname{cop} / \operatorname{kor} B$. Details of plasmid constructions are given in the text. $t s r$, thiostrepton resistance gene; mel, tyrosinase gene.

(b)

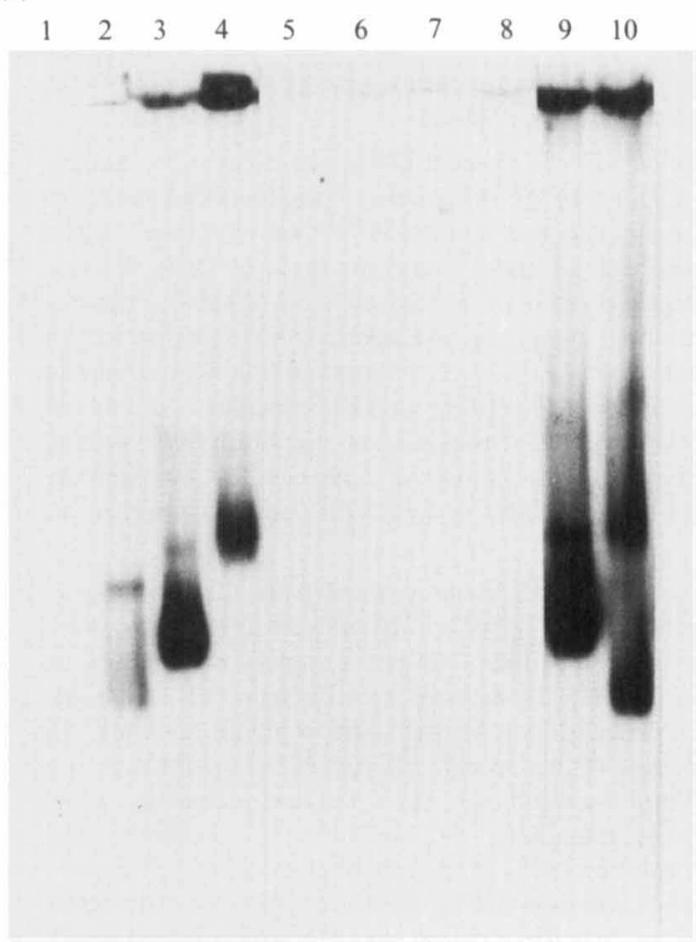

Fig. 2. Detection of ssDNA in S. lividans. (a) Agarose gel electrophoresis of S. lividans whole-cell lysates; the upper band is the chromosomal DNA and the lower, faster-migrating band is the plasmid DNA. (b) Southern biot (without pretreatment) of the same gel, probed with $\left[\alpha_{-}{ }^{32} \mathrm{P}\right] \mathrm{dCTP}$-labelled $\mathrm{pIJ} 702$ showing ssDNA accumulation for lysates in lanes $2,3,4,9$ and 10 . Lanes: 1 , pIJ303;2, pIJ702; 3, pQR410b; 4, pQR410a; 5, pQR411b; 6, pQR411a; 7, pQR421b; 8, pQR421a; 9, pQR422b; 10, pQR422a. Details of ssDNA isolation and detection are given in Methods. 

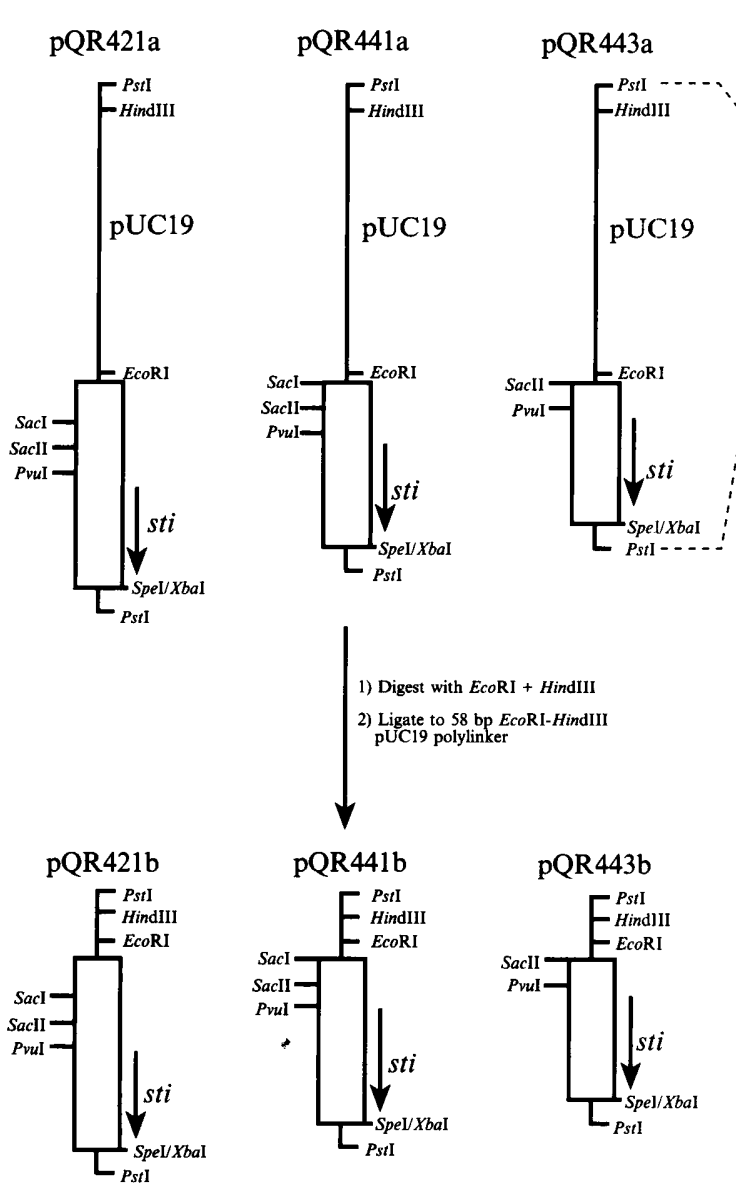

lysates containing $p Q R 411 a / b$ or $p Q R 421 a / b$. Thus, if $s t i$ is reinserted into pIJ702 in the correct orientation with respect to the basic replicon, a decrease in ssDNA production occurs, as seen in lysates containing $\mathrm{pQR} 411 \mathrm{a} / \mathrm{b}$ and $\mathrm{pQR} 421 \mathrm{a} / \mathrm{b}$, regardless of the presence or absence of cop/korB. This suggests that sti alone is sufficient for the efficient initiation of second-strand synthesis to form double-stranded plasmid derivatives, since no ssDNA was detected in $\mathrm{pQR} 421 \mathrm{a} / \mathrm{b}$ lysates.

If Cop/KorB is involved in copy number regulation as suggested by Deng et al. (1988), it would have to negatively control plasmid copy number in one of two ways: it could bind to the double-stranded form of $s t i$ and thus block the production of ssDNA intermediates by Rep; or it could bind to the single-stranded form of $s t i$ and thus inhibit the conversion of ssDNA to doublestranded plasmid DNA (which would lead to a pool of ssDNA in the cell). The former situation has been shown not to occur as Cop/KorB does not bind to doublestranded sti DNA in gel-retardation assays (Zaman, 1991; Zaman et al., 1992). The latter case also probably does not occur since there is no accumulation of ssDNA in lysates containing pQR411a/b (Fig. 2). Furthermore, from yields of plasmid DNA obtained for $\mathrm{Sti}^{+}$plasmids

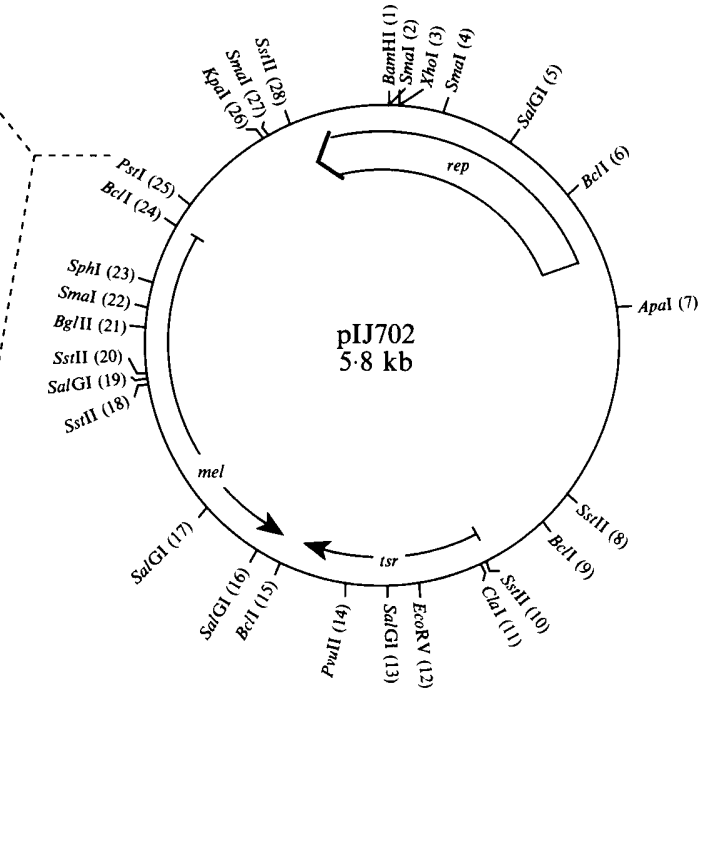

Fig. 3. Construction of $p Q R 441 a / b$ and $p Q R 443 a / b$ to delineate the upper limit of $s t i$. The straight arrows indicate the orientation of $s t i$ with respect to the pIJ702 replicon (rep; indicated by a curved broad arrow). Details of plasmid constructions are given in the text. $t s r$, thiostrepton resistance gene; mel, tyrosinase gene. with and without Cop/KorB, it would seem that Cop/KorB does not significantly alter plasmid copy number.

If $s t i$ is reinserted in the reverse orientation with respect to the basic replicon (pQR410a/b, pQR422a/b), then ssDNA accumulates in the cell, presumably because sti cannot be recognized as the site for second-strand synthesis in its inactive orientation. It should be noted that Deng et al. (1988) have claimed that the SpeI site (used to sub-clone sti in pQR417) lies within the $s t i$ determinant. However, our results suggest this is not the case since cleavage at the SpeI site does not disrupt Sti function and ssDNA is not detected in lysates containing pQR421a/b.

These results firstly confirm that $s t i$ is the site for second-strand initiation (ssi) and is active only in its natural orientation with respect to the basic replicon. Secondly, they show that Cop/KorB does not seem to play a role in the control of plasmid copy number through the sti locus since it does not bind either to the double-stranded form of $s t i$, which would inhibit second strand initiation (Zaman, 1991; Zaman et al., 1992), or to the single-stranded form of $s t i$, which would inhibit ssDNA conversion to double-stranded plasmids (this 


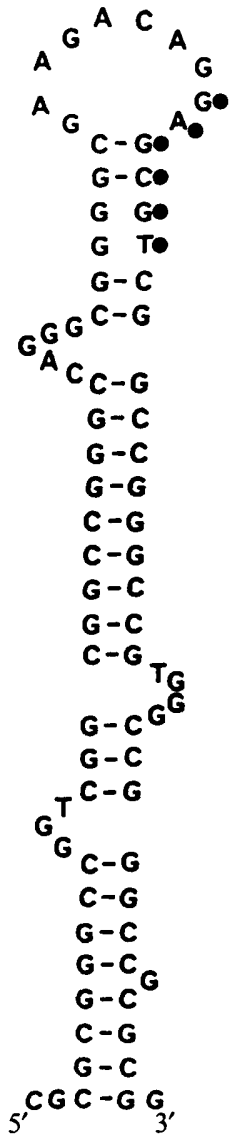

Fig. 4. Potential secondary structure of the sti region of pIJ101. The $0.53 \mathrm{~kb}$ SpeI-SacIl sti region was scanned for stable inverted repeats. The most stable stem-loop structure found within this defined $s t i$ region lies between nucleotides 7310 and 7385 on the pIJ101 sequence (Kendall \& Cohen, 1988). The identified stem-loop structure has a stability of $\Delta G=64 \mathrm{kcal} \mathrm{mol}^{-1}$ as defined by Tinoco et al. (1973). Filled circles indicate bases that are homologous to the TAGCGT consensus sequence found in ssi regions of several plasmids and phages (see Table 2)

work). Thirdly, they reveal that $s t i$ in either orientation and in the absence of Cop/KorB seems to stabilize the pIJ702-pUC8 shuttle vectors, since no rearrangements were detected in $S$. lividans.

\section{Stability of $\mathrm{Sti}^{+}$and $\mathrm{Sti}^{-}$plasmids in S. lividans}

The term plasmid instability is used for both structural instability (rearrangements of plasmid DNA) and segregational instability (loss of the plasmid during cell division). In this work, we have shown that sti in either orientation structurally stabilizes the pIJ702-pUC8 shuttle vectors which would otherwise rearrange and accumulate ssDNA in S. lividans (R. Barrallon, personal communication).

Plasmid segregational instability in unicellular bacteria is normally followed by plating samples on agar to reveal the proportion of colony-forming units that exhibit a plasmid-borne phenotype, e.g. antibiotic resistance. Since Streptomyces are filamentous micro-organisms and almost always form microscopically-sized clumps in most commonly used liquid media, a simple plating method does not work. This is because a colony on a plate is not derived from a single cell but from a clump in which only a small proportion of the mycelial filaments need to have a plasmid for a colony to be formed on selective agar. Since segregational instability is often preceded by a decrease in plasmid copy number, we have developed a method to measure plasmid copy number and therefore monitor plasmid stability throughout growth (Wrigley-Jones et al., 1992). The method is designed to measure all topoisomers of double-stranded DNA. Using this method, we have measured the copy number of the $\mathrm{Sti}^{+}$plasmid pIJ303 (pIJ101 with a thiostrepton resistance gene) and found it to increase from less than 200 to more than 400 copies per chromosome between the initial rapid growth phase and stationary phase (Wrigley-Jones et al., 1993). In comparison, the copy number for the $\mathrm{Sti}^{-}$plasmid pIJ702 increased from 100 to a maximum of 200 copies per chromosome but then declined to fewer than 100 copies per chromosome during stationary phase (WrigleyJones, 1991). These results show that pIJ702, which lacks the primary site for second-strand initiation, has a lower copy number than its parent and is therefore more likely to be lost during cell division. A similar decline in copy number during stationary phase was observed for two further $\mathrm{Sti}^{-}$plasmids, pMT605 and pMT608, both derivatives of pIJ702 with the agarase gene from $S$. coelicolor (Wrigley-Jones, 1991). This suggests that $\mathrm{Sti}^{-}$ plasmids have a lower copy number than $\mathrm{Sti}^{+}$plasmids because they cannot efficiently convert the pool of singlestranded intermediates to double-stranded plasmids.

\section{Location of the sti function}

Several further constructs were made in order to define more precisely where the sti determinant was located on the $0.7 \mathrm{~kb}$ SpeI-BclI fragment (Fig. 3). pQR417 was cut with $S a c I$ and HindIII, and the $0.6 \mathrm{~kb} s t i$ fragment ligated to pUC19 cut with the same enzymes (thereby removing approximately $100 \mathrm{bp}$ from the original sti fragment), creating pQR437. pQR437 and pIJ702 were digested with Pst $\mathrm{I}$, ligated, and used to transform E. coli. Constructs containing pIJ702 in both orientations were identified and named pQR441a and pQR442a, respectively. Only pQR441a was used in subsequent experiments as it possessed sti in the same orientation with respect to the basic replicon (Fig. 3). To remove the pUC19 component, pQR441a was digested with EcoRI-HindIII and ligated to the $58 \mathrm{bp}$ EcoRI-HindIII pUC19 poly- 
Table 2. Nucleotide sequence comparison of DNA regions containing ssi sites of phages and plasmids

The consensus sequence is shown in bold.

\begin{tabular}{|c|c|c|c|}
\hline Plasmid/phage & ssi nucleotide sequence & Host & Reference \\
\hline pE194 & GCGAAAGTAGTAGCGACAGCTATTAA & Staphylococcus & \\
\hline pC221 & AGCGGTCAGATAGCGTCAGCTA ICAA & Staphylococcus & \\
\hline pC194 & AATGTCGGCATAGCGTGAGCTATTAA & Staphylococcus & \\
\hline pLS1 & CGAAAGGCTTTAGCGTTTCGGACGGA & Streptococcus & del Solar et al. (1987) \\
\hline pLS1 (att) & TTCTTATCGTTAGCGTGCTGTCATTC & Streptococcus & \\
\hline$\phi \times 174$ & GTAAAAATTTTAATTTTTGCCGCTGA & E. coli & \\
\hline M13 & GGGCTCCCTTTAGGGTTCCGATTTAG & E. coli & \\
\hline pACYC184 & TCGAACGACCGAGCGTAGCGAGTCAG & E. coli & \\
\hline p15A & TCGAACGACCGAGCGTAGCGAGTCAG & E. coli & Bahk et al. (1988) \\
\hline pBR322 & CCGAACGACCGAGCGCAGCGAGTCAG & E. coli & \\
\hline pIJ101 & GCGAAGACAGGAGCGTCGGCCGGGCC & S. lividans & This work \\
\hline Consensus & TAGCGT & & \\
\hline
\end{tabular}

linker, producing pQR441b (Fig. 3). pQR441a and $\mathrm{pQR} 441 \mathrm{~b}$ both successfully transformed $S$. lividans to thiostrepton resistance and were structurally stable from restriction map analysis.

pQR437 was digested with SacI and SacII (removing a further $65 \mathrm{bp}$ from the original sti fragment) and the $3.23 \mathrm{~kb}$ fragment was ligated to the $14 \mathrm{bp} \mathrm{SacI-SacII}$ pBluescript polylinker, creating $\mathrm{pQR} 438$. $\mathrm{pQR} 438$ was ligated to $\mathrm{pIJ} 702$ via the PstI site. Again constructs containing pIJ702 in both orientations were found in $E$. coli and named pQR443a and pQR444a, respectively. Only pQR443a was studied since it possessed sti in the same orientation with respect to the basic replicon (Fig. 3). To remove the pUC19 component, pQR443a was digested with EcoRI and HindIII and ligated to the EcoRI-HindIII pUC19 polylinker, producing pQR443b (Fig. 3). Both pQR443a and pQR443b successfully transformed $S$. lividans to thiostrepton resistance and were structurally stable from restriction map analysis.

Total DNA was prepared from $p Q R 441 \mathrm{a} / \mathrm{b}$ and $\mathrm{pQR} 443 \mathrm{a} / \mathrm{b}$, run on an agarose gel (with pIJ702 and pIJ303 as controls), and blotted directly onto a nylon membrane. The membrane was probed with $[\alpha-$ ${ }^{32} \mathrm{P}$ ]dCTP-labelled pIJ702 (data not shown). No ssDNA was detected in lysates containing $p Q R 441 a / b$ or $\mathrm{pQR} 443 \mathrm{a} / \mathrm{b}$, indicating that the deletions made to the original $0.7 \mathrm{~kb} S p e I-B c l I$ sti fragment were located outside the functional site for second-strand synthesis. Thus, this $0.53 \mathrm{~kb}$ SpeI-SacII fragment defines the upper limit of the sti determinant.

Almost all ssi sequences contain potential stem and loop structures and both the nucleotide sequence and secondary structure may play critical roles in the functional activity of these signals (Marians et al., 1982; van der Ende et al., 1983; Stuitje et al., 1984; del Solar et al., 1987; Gruss et al., 1987; Bahk et al., 1988; Boe et al., 1989). Several potential stem-loop structures were identified within the $0.53 \mathrm{~kb} S p e I-S a c$ II sti sequence, the most stable having a $\Delta G$ of $-64 \mathrm{kcal} \mathrm{mol}^{-1}$ $\left(-268 \mathrm{~kJ} \mathrm{~mol}^{-1}\right)$, which could form the stem-loop structure in vivo shown in Fig. 4. This stem-loop structure contains five out of six bases which appear in a hexanucleotide consensus sequence (TAGCGT) found in ssi sites of staphylococcal (Gruss et al., 1987), streptococcal (del Solar et al., 1987), and E. coli (Bahk et al., 1988) plasmids. A comparison of the hairpin loop and the sites of second-strand synthesis of these plasmids is shown in Table 2. Our results suggest that the DNA sequence shown in Fig. 4 may therefore be the ssi sequence of pIJ101.

In conclusion, functional ssi sites are essential for replication and may be important for maintaining plasmid structural stability by preventing the accumulation of large amounts of highly recombinogenic ssDNA. The observations reported in this paper may contribute to the development of efficient and stable cloning vectors based on pIJ702 for use in S. lividans.

S. Z. received support from the Overseas Research Scholarship (UK). H.R. and J.M.W. thank the SERC for a grant from their 'Antibiotics and Recombinant DNA Initiative' for supporting some of this work. We are extremely grateful to Dr Rita Barallon for constructing and characterizing the pIJ702-pUC8 shuttle vectors. We would also like to thank Dr Sami Bahri for his comments on the manuscript.

\section{References}

Bahk, J. D., Sakai, H. \& Komano, T. (1988). Plasmid paCYC184 contains an ssi signal for initiation of single-stranded phage DNA replication. Gene 65, 93-99.

BIBB, M. J., WARD, J. M. \& Hopwood, D. A. (1978). Transformation of plasmid DNA into Streptomyces protoplasts at high frequency. Nature, London 274, 398-400.

BIRNBOIM, H. C. \& Doly, J. (1979). A rapid alkaline extraction procedure for screening recombinant plasmid DNA. Nucleic Acids Research 7, 1513-1523.

Boe, L., Gros, M. F., Te Riele, H., Ehrlich, S. D. \& Gruss, A. (1989). Replication origins of single-stranded-DNA plasmid pUB110. Journal of Bacteriology 171, 3366-3372.

ChATER, K. F. (1990). The improving prospects for yield increase by genetic engineering in antibiotic-producing streptomyces. Bio/ Technology 8, 116-121. 
DENG, Z., Kieser, T. \& Hopwood, D. A. (1988). 'Strong incompatibility' between derivatives of the Streptomyces multi-copy plasmid pIJ101. Molecular and General Genetics 214, 286-294.

Devine, K., Hogan, S., Higgins, D. \& McDonell, D. (1989). Replication and segregational stability of the Bacillus plasmid pBAA1. Journal of Bacteriology 171, 1166-1172.

van der Ende, A., Teertstra, R., van Der Avoort, H. G. A. M. \& WeISBEEK, P. J. (1983). Initiation signals for complementary strand DNA synthesis on single-stranded plasmid DNA. Nucleic Acids Research 11, 4957-4975.

Gros, M. F., TE RIELe, H. \& Ehrlich, S. D. (1987). Rolling circle replication of the single-stranded DNA plasmid pC194. EMBO Journal 6, 3863-3869.

Gruss, A. D. \& EhrLICH, S. D. (1989). The family of highly interrelated single-stranded deoxyribonucleic acid plasmids. Microbiological Reviews 53, 231-241.

Gruss, A. D., Ross, H. F. \& Novick, R. P. (1987). Functional analysis of a palindromic sequence required for normal replication of several staphylococcal plasmids. Proceedings of the National Academy of Sciences of the United States of America 84, 2165-2169.

Hanahan, D. (1983). Studies on transformation of Escherichia coli with plasmids. Journal of Molecular Biology 166, 557-580.

Hopwood, D. A., Kieser, T., Wright, H. M. \& BibB, M. J. (1983). Plasmids, recombination and chromosome mapping in Streptomyces lividans 66. Journal of General Microbiology 129, 2257-2269.

Hopwood, D. A., BibB, M. J., Chater, K. F., Kieser, T., Bruton, C. J., Kieser, H. M., Lydiate, D. J., Smith, C. P., WARD, J. M. \& SCHREMPF, H. (1985). Genetic Manipulation of Streptomyces: a Laboratory Manual. Norwich: John Innes Foundation.

Katz, E., Thompson, C. J. \& Hopwood, D. A. (1983). Cloning and expression of the tyrosinase gene from Streptomyces antibioticus in Streptomyces lividans. Journal of General Microbiology 129, 2703-2714.

Kendall, K. J. \& Cohen, S. N. (1987). Plasmid transfer in Streptomyces lividans: identification of a kil-kor system associated with the transfer region of pIJ101. Journal of Bacteriology 169, 4177-4183.

Kendall, K. J. \& CoHEN, S. N. (1988). Complete nucleotide sequence of the Streptomyces lividans plasmid pIJ101 and correlation of the sequence with genetic properties. Journal of Bacteriology $\mathbf{1 7 0}$, 46344651 .

KIESER, T. (1984). Factors affecting the isolation of CCC DNA from Streptomyces lividans and Escherichia coli. Plasmid 12, 19-36.

Kieser, T., Hopwood, D. A., Wright, H. M. \& Thompson, C. J. (1982). pIJ101, a multi-copy broad host range Streptomyces plasmid: functional analysis and development of DNA cloning vectors. Molecular and General Genetics 185, 223-228.

Lee, Y. H. W., Tzecheng, Z. Y., Wang, S. C., Cheng, W. L. \& Chen, C. W. (1986). Structural stability of heterologous genes cloned in Streptomyces plasmid pIJ702. Biochemical and Biophysical Research Communications 140, 372-378.

Maniatis, T., Fritsch, E. F. \& Sambrook, J. (1982). Molecular Cloning, a Laboratory Manual. Cold Spring Harbor, NY: Cold Spring Harbor Laboratory.

Marians, K. J., Soeller, W. \& Zipursky, S. L. (1982). Maximal limits of the Escherichia coli replication factor $\mathrm{Y}$ effector sites sequences in pBR322 DNA. Journal of Biological Chemistry 257, 5656-5662.

MoRrison, D. A. (1979). Transformation and preservation of competent bacterial cells by freezing. Methods in Enzymology 68, 326-331.

Novick, R. P. (1989). Staphylococcal plasmids and their replication. Annual Review of Microbiology 43, 537-565.

Pigac, J., Vujaklija, D., Toman, Z., Gamulin, V. \& Schrempf, H.
(1988). Structural instability of a bifunctional plasmid pZGl and single-stranded DNA formation in Streptomyces. Plasmid 19, 222-230.

TE Riele, H., Michel, B. \& Ehrlich, S. D. (1986a). Single-stranded plasmid DNA in Bacillus subtilis and Staphylococcus aureus. Proceedings of the National Academy of Sciences of the United States of America 83, 2541-2545.

Te Riele, H., Michel, B. \& Ehrlich, S. D. (1986b). Are singlestranded circles intermediates in plasmid DNA replication? EMBO Journal 5, 631-637.

Del Solar, G. H., Puyet, A. \& Espinosa, M. (1987). Initiation signals for the conversion of single stranded to double stranded DNA forms in the streptococcal plasmid pLS1. Nucleic Acids Research 15, $5561-5580$.

SOUTHERN, E. (1975). Detection of specific sequences among DNA fragments separated by gel electrophoresis. Journal of Molecular Biology 98, 503-517.

STEIN, D. A. \& COHEN, S. N. (1990). Mutational and functional analysis of the kor $A$ and $k o r B$ gene products of Streptomyces plasmid pIJ101. Molecular and General Genetics 222, 337-334.

Stein, D. A., Kendall, K. J. \& Cohen, S. N. (1989). Identification and analysis of transcriptional regulatory signals for the kil and kor loci of Streptomyces plasmid pIJ101. Journal of Bacteriology 171, 5768-5775.

Stuttje, A. R., Weisbeek, P. J. \& Meier, M. (1984). Initiation signals for complementary strand DNA synthesis in the region of the replication origin of the Escherichia coli chromosome. Nucleic Acids Research 12, 3321-3332.

Thompson, C. J., Kieser, T., Ward, J. M. \& Hopwood, D. A. (1982). Physical analysis of antibiotic-resistance genes from Streptomyces and their use in vector construction. Gene 20, 51-62.

Tinoco, I., JR, Borer, P. N., Dengler, B., LeVine, M. D., Uhkenbeck, O. C., Crothers, D. M. \& Gralla, J. (1973). Improved estimation of secondary structure in ribonucleic acids. Nature, London $\mathbf{2 4 6}$, $40-41$.

Томісн, P. K. (1981). Streptomyces cloning: useful recombinant DNA systems and a summation of cloned genes. Antimicrobial Agents and Chemotherapy 32, 1465-1471.

VieIRA, J. \& Messing, J. (1982). The pUC plasmids: an M13mp7 derived system for insertion mutagenesis and sequencing with synthetic universal primers. Gene 19, 259-268.

Wrigley-JONES, C. A. (1991). Plasmid vector stability in Streptomyces lividans fermentations. $\mathrm{PhD}$ thesis, University College, London, UK.

Wrigley-Jones, C. A., Richards, H., Thomas, C. R. \& Ward, J. M. (1992). A method for plasmid copy number determination in recombinant Streptomyces. Journal of Microbiological Methods 16, 69-80.

Wrigley-Jones, C. A., Richards, H., Thomas, C. R. \& Ward, J. M. (1993). Stability of plasmid vector pIJ303 in Streptomyces lividans TK24 during laboratory scale fermentations. Biotechnology and Bioengineering 41, 148-155.

YanisCH-Perron, C., Vieira, J. \& Messing, J. (1985). Improved M13 phage cloning vectors and host strains. Nucleotide sequences of the M13mp18 and pUC19 vectors. Gene 33, 103-119.

ZAMAN, S. (1991). Genetics and molecular biology of the Streptomyces lividans plasmid pIJ101. $\mathrm{PhD}$ thesis, University College, London, UK.

Zaman, S., Richards, H. \& Ward, J. M. (1992). Expression and characterisation of the kor $B$ gene product from the Streptomyces lividans plasmid pIJ101 in Escherichia coli and determination of its binding site on the korB and kilB promoters. Nucleic Acids Research 20, 3693-3700.

Zaman, S., Richards, H. \& Ward, J. M. (1993). Identification of the minimal replicon of the streptomycete plasmid pIJ101. Plasmid (in the Press). 